\title{
A scalable life cycle inventory of an electrical automotive traction machine-Part I: design and composition
}

\author{
Anders Nordelöf $^{1}$ (D) Emma Grunditz ${ }^{2}$ - Anne-Marie Tillman ${ }^{1}$ • Torbjörn Thiringer ${ }^{2}$. \\ Mikael Alatalo ${ }^{2}$
}

Received: 15 July 2016 / Accepted: 23 March 2017 / Published online: 5 April 2017

(C) The Author(s) 2017. This article is published with open access at Springerlink.com

\begin{abstract}
Purpose A scalable life cycle inventory (LCI) model of a permanent magnet electrical machine, containing both design and production data, has been established. The purpose is to contribute with new and easy-to-use data for LCA of electric vehicles by providing a scalable mass estimation and manufacturing inventory for a typical electrical automotive traction machine. The aim of this article (part I of two publications) is to present the machine design, the model structure, and an evaluation of the models' mass estimations.

Methods Data for design and production of electrical machines has been compiled from books, scientific papers,
\end{abstract}

\section{Preamble}

This series of two articles presents a new scalable life cycle inventory (LCI) data model of an electrical automotive traction machine, available to download from the CPM database of the Swedish Life Cycle Center. Part I describes how the LCI model was established and the type of results it provides, including the underlying permanent magnet synchronous machine (PMSM) design and the structure of the LCI data model. Part II presents new primary production data and revised literature data to cover the complete PMSM motor manufacturing chain, including magnet fabrication, electrical steel production, and a comprehensive survey of an electrical motor factory. It also discusses the data collection methods and explains the selection of system boundaries and how to link the gate to gate inventory to the Ecoinvent database version 3 .

Responsible editor: Zbigniew Stanislaw Klos

Anders Nordelöf

anders.nordelof@chalmers.se

1 Department of Energy and Environment, Division of Environmental Systems Analysis, Chalmers University of Technology, 41296 Gothenburg, Sweden

2 Department of Energy and Environment, Division of Electric Power Engineering, Chalmers University of Technology,

41296 Gothenburg, Sweden benchmarking literature, expert interviews, various specifications, factory records, and a factory site visit. For the design part, one small and one large reference machine were constructed in a software tool, which linked the machines' maximum ability to deliver torque to the mass of its electromagnetically active parts. Additional data for remaining parts was then gathered separately to make the design complete. The two datasets were combined into one model, which calculates the mass of all motor subparts from an input of maximum power and torque. The range of the model is $20-200 \mathrm{~kW}$ and $48-477 \mathrm{Nm}$. The validity of the model was evaluated through comparison with seven permanent magnet electrical traction machines from established brands.

Results and discussion The LCI model was successfully implemented to calculate the mass content of 20 different materials in the motor. The models' mass estimations deviate up to $21 \%$ from the examples of real motors, which still falls within expectations for a good result, considering a noticeable variability in design, even for the same machine type and similar requirements. The model results form a rough and reasonable median in comparison to the pattern created by all data points. Also, the reference motors were assessed for performance, showing that the electromagnetic efficiency reaches 96-97\%. Conclusions The LCI model relies on thorough design data collection and fundamental electromagnetic theory. The selected design has a high efficiency, and the motor is suitable for electric propulsion of vehicles. Furthermore, the LCI model generates representative mass estimations when compared with recently published data for electrical traction machines. Hence, for permanent magnet-type machines, the LCI model may be used as a generic component estimation for LCA of electric vehicles, when specific data is lacking.

Keywords Electric · Electrical · Inventory · IPM · IPMSM · Life cycle assessment $\cdot$ Machine $\cdot$ Magnet $\cdot$ Mass $\cdot$ Material 
composition $\cdot$ Model $\cdot$ Motor $\cdot$ Scalable $\cdot$ Weight .

Permanent $\cdot$ PM $\cdot$ PMSM $\cdot$ Vehicle

\section{Introduction}

\subsection{Background}

Life cycle assessment (LCA) of electrified vehicles for road transport, for example plug-in hybrid or fully electric passenger cars, is an active research area where many case studies are conducted and published (Hawkins et al. 2012; Nordelöf et al. 2014). However, few well-populated and transparent inventory datasets have been published for electric vehicles and different electric powertrain components. This relates both to the composition of materials in the components and their production processes (Hawkins et al. 2012). Inventory data for version 3 of the Ecoinvent database, the most used and acknowledged life cycle inventory database worldwide (Weidema et al. 2013), has been published recently by Del Duce et al. (2016) for various components of an electric powertrain such as an electric motor and different types of power electronic devices, including production. The electrical machine data represents a permanent magnet synchronous machine (PMSM), which is the most common type of motor for electric vehicles (Chan 2007; Miller 2013b). Still, this dataset is limited in scope since it has been derived for an electric vehicle of a specific size and class, e.g., a Volkswagen Golf or similar, and it represents a fixed component mass, material composition, and set of performance parameters (Del Duce et al. 2016; Weidema et al. 2013).

In contrast, components differ between vehicle types and sizes in order to fulfil different powertrain requirements, both in terms of weight and in terms of composition of subparts and materials. Altered component design implies that upstream production efforts will change. Data on weight and composition of components and subparts is required to establish a representative cradleto-gate life cycle inventory. However, such data can be difficult to obtain while public automotive powertrain specifications are commonly expressed in terms of power or torque.

Concluding, there is lack of life cycle inventory data for electric powertrain components which can be directly generated from more easily acquired engineering requirements, such as power. Additionally, there is a lack of inventory data for electrical traction machines, in terms of material composition and mass, when these engineering requirements change, matching different types of automotive applications.

\subsection{The purpose of a scalable LCI model}

The purpose of the scalable LCI model is to provide mass composition data and manufacturing data for a typical electrical machine design for automotive traction applications, especially for all-electric driving with a single motor. The intention is to complement the few existing datasets and assist LCA evaluation of electric powertrains through the generation of data for different sized machines.

The model was established as a response to the general lack of data for LCA of electrified powertrains and more specifically for electrical traction machines. It contains both design and production data and generates data on motors ranging in power from 20 to $200 \mathrm{~kW}$ and in torque from 48 to $477 \mathrm{Nm}$, i.e., from a small electric passenger vehicle up to, for example, a small electrically propelled city bus or truck (Volvo 2015). The resulting datasets represent the gate-to-gate production of the motor, from materials to complete motor, to be used as an estimate of any PMSM designed for electric propulsion, if it falls within the range for power and torque requirements for which the model is valid. On the other hand, adjacent powertrain components, i.e., the motor controller or a gearbox, are not included. The inventory model is available as a spreadsheet file in Microsoft Excel, which can be downloaded from the SPINE@CPM LCA Database, ${ }^{1}$ together with an extensive model report (Nordelöf et al. 2016). The model report provides relevant electrical machine theory summarized for LCA practitioners, along with all the details on how the data model has been established in terms of motives for design selections and other model assumptions, and descriptions of the data collection.

Another aim was to collect and present new manufacturing data with sufficient resolution to identify the effect of change in motor size within production, especially at the motor factory. Hence, in addition to being used as a part of the overall data model, manufacturing data can be used independently. In both cases, it is to conduct LCA and pinpoint key environmental issues with focus on this life cycle stage.

Finally, an important objective was to make the model easy to use by LCA practitioners. For this reason, the manufacturing processes have been followed upstream to a point where LCI data for representative material production exist in the Ecoinvent database version 3 (Weidema et al. 2013).

\subsection{Aim and content of the article series}

The aim of this part of the publication, article part I, is to present a description of how the scalable LCI data model was established and the results it provides. It explains the underlying electrical machine design and the structure of the LCI data model. The main focus is set on the establishment of the design data. The validity of the model is examined through a comparison with data for machines released within the last 3 years, dating from the project start. Moreover, both technical scope and user options are discussed.

\footnotetext{
${ }^{1}$ Provided by the Swedish Life Cycle Center at

http://cpmdatabase.cpm.chalmers.se/Scripts/sheet.asp?ActId=JT-2016-0621-39
} 
Subsequently, article part II presents new primary production data for PMSM motor manufacturing, electrical steel production, die casting of aluminum housings, and enameling of copper wire, along with the data collection procedures. Part II also describes the data for the permanent magnet production chain, based on previously published inventory data for LCA (Sprecher et al. 2014a, b; NETL 2015), but revised and updated with original data to match the $\mathrm{Nd}(\mathrm{Dy}) \mathrm{FeB}$ type used in automotive applications. Finally, part II of the article series explains the recommendations as to how to link the gate-togate inventory to Ecoinvent 3.

The level of technical detail throughout both publications was selected to address a broad target group including LCA practioners novel to electric motor terminology, as well as electrical power engineers aiming to use LCA results. Because of this multidisciplinary ambition of the work, the model report contains not only many technical details, but also simple explanations of terms and basic theory (Nordelöf et al. 2016).

\section{Methods}

The development of the LCI model required many significant methodological selections, both at the overall level and regarding details. These are described in the following chapter, also including the model structure and briefly how the modelled is used. Please turn to Fig. 1 for orientation when references are made to specific electrical machine parts.

\subsection{Challenges and overall modelling approach due to inherent design variability}

Development of electrical machines involves a large number of design variables including detailed geometrical tuning and material property considerations. It is a multi-objective engineering process with conflicting goals, and there is no single optimal solution fulfilling all desired requirements (Sizov et al. 2011; Ramakrishnan et al. 2016). Instead, there is typically a domain of solutions where the application and ad hoc trade-offs play an important role. This inherent characteristic of motor design poses a large challenge when the aim is to create an easy-to-use and scalable design model for LCA.

However, the original hypothesis of this project was that if the technical scope is sensibly delimited to a specific motor type and application area, it is possible to establish a design model for electric propulsion of vehicles that is both satisfactorily generic and relevant for LCA purposes. In such a setup, the operating range must be well defined and most parameters kept fixed in the form of a "standard" design. Still, the precision of the model's mass predictions will be limited due the inherent variability traits. More specifically, also within the scope of a typical design domain for a specific motor type and application area, the exact arrangement of the torque producing "active" parts is variable. Sizov et al. (2011) showed that by tuning 11 different design parameters in the rotor and stator cores, starting from the same basic PMSM design and magnet type, the total mass of the active parts differed up to $25 \%$ in motors producing the same torque. Furthermore, the size of the housing varies with several factors, e.g., the design of the cooling system, adaptions for vehicle assembly, and integration with other powertrain parts. As an example, data $^{2}$ from Burress et al. (2011), Miller (2013a), and Shimizu et al. (2013) report that the housing of the 2011 Nissan Leaf was $36 \%$ heavier than that of the 2008 Lexus LS $600 \mathrm{~h}$, despite that both motors had the same outer volume, and the Leaf active parts occupied a larger volume inside the housing (Ozpineci 2014). Also, the definitions of "maximum torque" and "maximum power" are not standardized in the automotive industry. In some cases, machines can have the same performance although they have different ratings.

As a result, the target for the prediction accuracy of the model was set to be $\pm 25 \%$ based on engineering judgement, and all comparisons with real-world motors falling within that range were regarded as a satisfactory result.

\subsection{Working procedure, model structure, and use}

The LCI data model project was conducted as a collaboration between researchers with different expertise, both LCA methodology and electrical machine design. Component design data was compiled from theory books, technology benchmarking literature, scientific papers, experts in industry, and product descriptions Additionally, production data was collected from industry in form of documents, site visit notes, more expert interviews, machine specifications, instruction films, and textbook descriptions. These two different types of data (design and production) were then combined into one scalable LCI model. It requests the user to enter a value for maximum power and optionally the torque (which allows for an adjustment of the operation voltage and base speed) (for an explanation of the electromagnetic terms and principles, please read the model report (Nordelöf et al. 2016)). Both power and torque are relatively easily accessible electrical machine parameters, as they are a part of marketing information. The model input request box is shown in Fig. 2. In return, by one button click, the model provides a gate-to-gate life cycle inventory for the production of an internal permanent magnet synchronous electrical machine, together with the mass configuration of the machine and recommendations for how to link the inventory to the Ecoinvent's database version 3 (Weidema et al. 2013), to create a complete cradle-to-gate LCI. The overall structure of the LCI model is shown in Fig. 3. It also demarcates the difference in focus of part 1 and part 2 in the article series.

\footnotetext{
${ }^{2}$ Compiled in Table 14 of the model report (Nordelöf et al. 2016).
} 
Fig. 1 Exploded sketch of the selected PMSM design

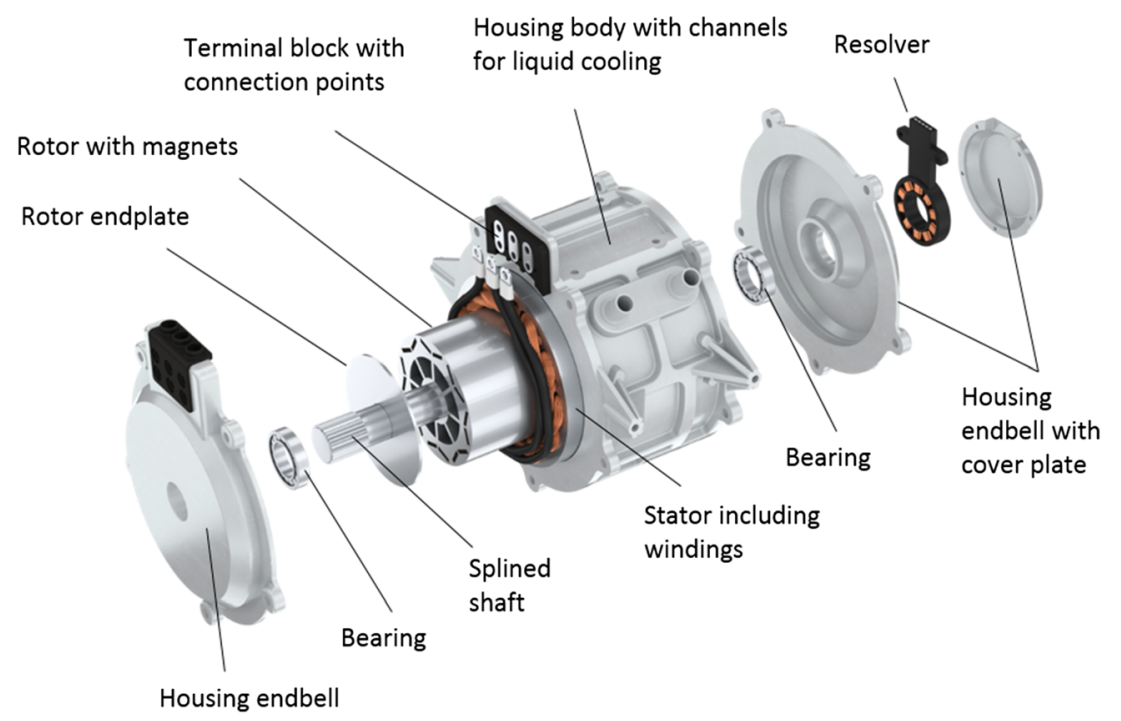

In the default setting, the LCI model calculates an inventory from the input of a maximum required motor power with the motor base speed set to $4000 \mathrm{rpm}$. No torque value must be entered; instead, the torque is derived from the power and the speed by the model (for an explanation of the electromagnetic terms and principles, please read the model report (Nordelöf et al. 2016)). However, if a specific base speed is known, the user may provide values for both maximum power and maximum torque, which implicitly will alter the base speed and the rated voltage. Such combined input is allowed as long as it results in a base speed within 3000-5000 rpm, which has been judged as a design validity span by the authors.

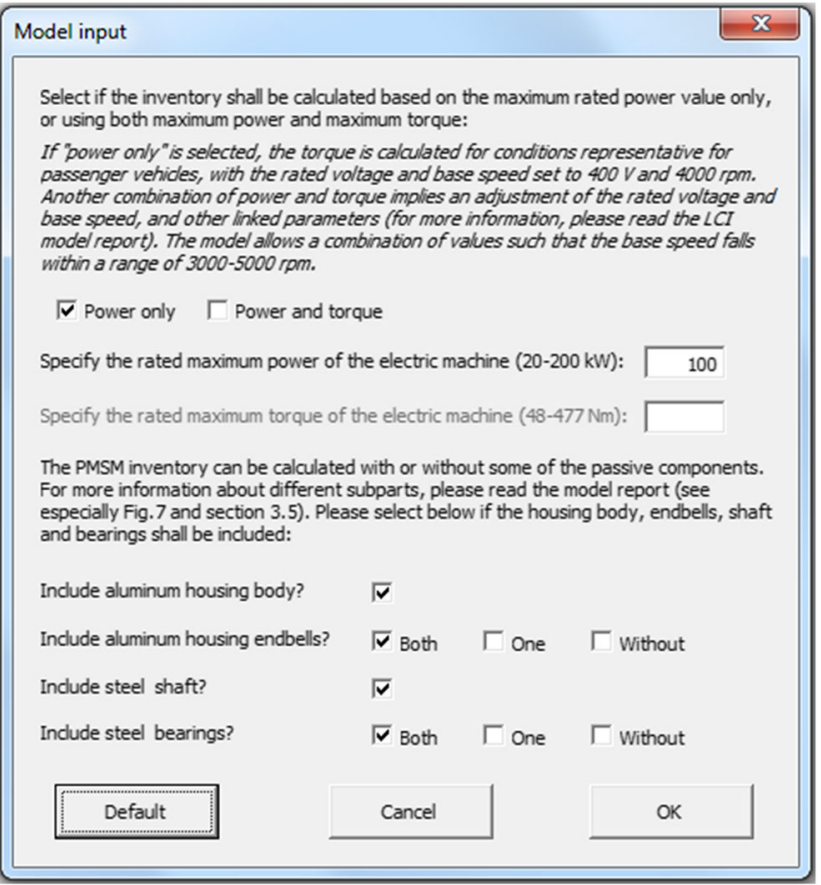

Fig. 2 The model input box
In order to establish a scalable model covering a useful power range, two motors, referred to as the "small" and the "large" reference machines, were constructed and evaluated for electrical and magnetic properties in ANSYS Maxwell (ANSYS 2015), a software tool for computational design and evaluation of electrical machine performance. The principal design was established based on observations of existing electrical traction machine designs, from disassembly of existing machines and in published reports, e.g., benchmarking literature (Burress et al. 2011; Burress and Campbell 2013; Miller 2013b; Ozpineci 2014) to be as generic as possible for a PMSM, as judged by the authors. The two reference machines have the same relative formation of the cross-section geometries but differ in diameter and length of the machine cores. This way of establishing the model is in line with how electrical traction machines often are developed. Tools for making the steel laminations are very expensive, and therefore, suppliers typically only offer machines with certain fixed diameters. However, the length can more easily be adjusted in order to deliver the desired power level (Hendershot and Miller 2010).

The design tool calculations provided the key link between the mass of the electromagnetically active parts in the design and the ability of the machine to deliver a specific maximum torque and power. Hence, this mass is referred to as active and consists of the amount of electrical steel in the stator and rotor cores, the copper in the stator slots, and the permanent magnets in the rotor. However, there are also electromagnetically passive parts in the motor, such as end-windings, insulation, shaft, bearings, housing, etc. Data on their weight and composition did not come from the design tool calculations, but was collected from electrical machine design literature, industrial benchmarking reports, subpart catalogues, and expert interviews. The passive parts were then combined with the active parts into a complete design. 
Fig. 3 The structure of the LCI model and the division of focus between article part I and II

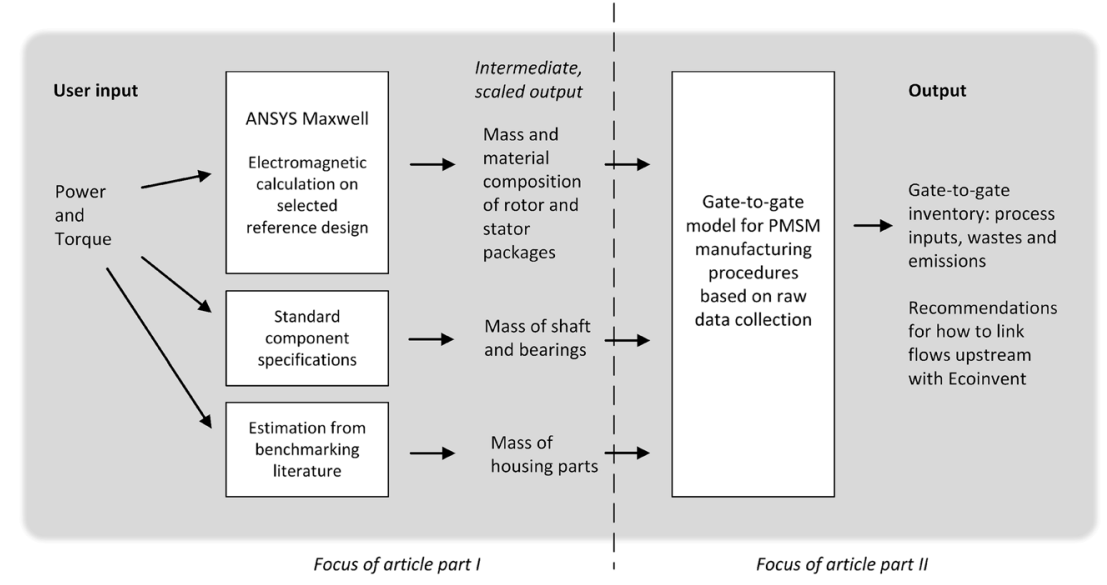

\subsection{Lengthwise scaling of the reference machines, fixed design selections, and model validation}

First, the two reference machines were modelled with different diameters and nominal lengths, matching a power of 40 and $100 \mathrm{~kW}$, with the base speed set to $4000 \mathrm{rpm}$, and a nominal DC system voltage of $400 \mathrm{~V}$, i.e., values representative for a passenger vehicle. Next, a span for torque and power was calculated for each of the two machines by scaling their active length up to the double nominal length and down to half of it; $20-80 \mathrm{~kW}$ and $48-191 \mathrm{Nm}$ for the small machine and 50-200 kW and 119-477 Nm for the large machine. This resulted in two separate sets of electrical machine data, linking the requirement for maximum torque to the mass of each active constituent. Subsequently, these two datasets were combined, in order to establish one seamless model for the entire torque and power span. This was done through a merger of the two datasets within the overlapping span of 119$191 \mathrm{Nm}(50-80 \mathrm{~kW}$ at $4000 \mathrm{rpm})$, by shifting over from the small to the large machine in a stepwise interpolation of the mass data, i.e., corresponding to $100 \%$ of the small reference machine at $50 \mathrm{~kW}$ and $100 \%$ of the large reference machine at
$80 \mathrm{~kW}$. As a consequence, a real average (50\% of each) between the two occurs at $65 \mathrm{~kW}$ and $155 \mathrm{Nm}$. Figure 4 shows a sketch of the scaling principle including the section where the reference datasets were merged into one.

Other important, but fixed, design selections were the use of a so-called distributed winding of the copper coils in the stator slots and the parameter setting of the current density. Distributed windings are extensively used for all sorts of electrical machines and can be termed as the "conventional" design, although other ways of inserting copper into the stator are also on the rise for many applications (Choe et al. 2012; Barré and Napame 2016; Tong 2014). The current density was set to a maximum of $20 \mathrm{~A} / \mathrm{mm}^{2}$ for all calculations, as a median based on observations of real motor values presented in benchmarking literature (Ozpineci 2011). Moreover, in a vehicle, the maximum achievable power at any given moment will strongly depend on the voltage the battery is able to deliver. The choice of using a constant DC voltage, representing the rated battery performance, then pushes the maximum power to the upper level of what is reachable, with the machine itself setting the limit. Important geometric properties and other key assumptions of the reference machines are presented in Table 1.
Fig. 4 Schematic overview of how the reference machines were scaled in length over different spans, to adjust their power and torque production, and the overlap where the datasets have been merged to create one seamless model

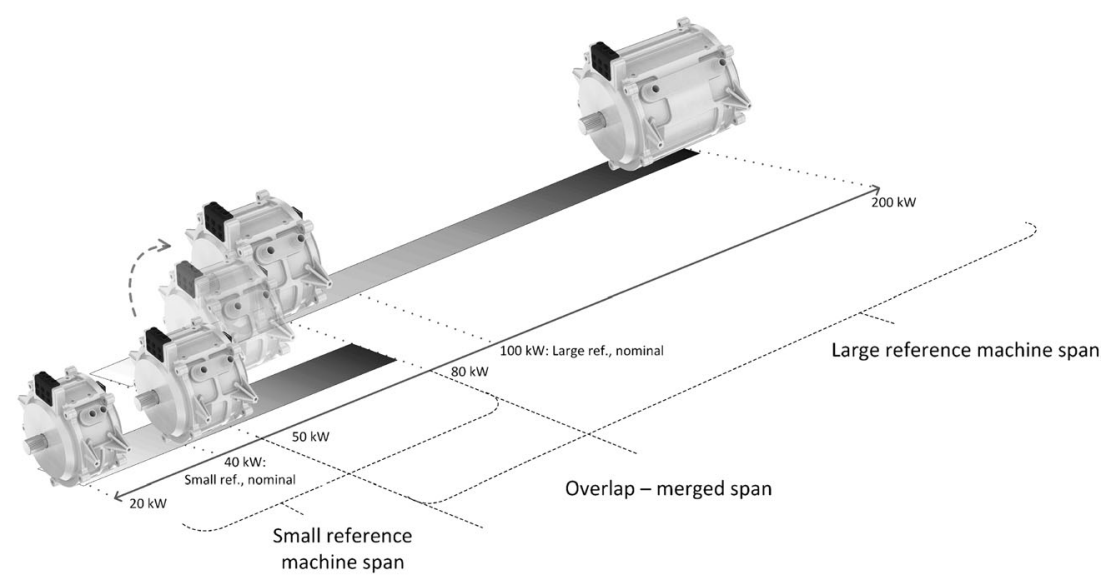


The torque value is used to calculate the weights of almost all subparts and materials in the model. Most passive parts are geometrically coupled to the active parts and scale with them as torque and geometry change. Other passive parts scale directly with torque or have constant masses. The housing is an exception. Since one of its key roles is to provide proper cooling, it is scaled in relation to power, which in turn relates closely to heat losses.

Two passive parts that together contribute to around $40 \%$ of the total mass, the shaft and the housing, can be deselected from the calculation by the model user. This is because their design offers larger variability than other parts, for example depending on packing and cooling solutions. They may also be integrated with other powertrain components. The option to deselect the shaft and the housing increases the flexibility of the LCI model, while increasing precision should more specific data be gathered separately by the model user.

In order to validate the model, data was gathered for seven PMSM traction machines where the maximum power and torque were available, together with the electric motor mass (the total mass including shaft and housing, but without the gearbox) from established brands and sub-suppliers within the last 3 years (dating from the project start, i.e., 2013 and onwards). Model calculations for the comparisons were based on input of both power and torque. However, in line with the stated model limitations, only machines where the combination of the power and torque gave an estimated base speed within 3000-5000 rpm were included.

\section{Design description and data collection}

This chapter presents a summary of how the design data was generated and compiled. For full details, and an explanation of the electromagnetic terms and principles, please read the model report (Nordelöf et al. 2016). In addition, please refer to Fig. 1 for all descriptions of parts presented in this chapter.

\subsection{The electrical steel cores}

The two main active parts of the electrical machine are the stator and the rotor. The bulk of these parts, referred to as the core, is normally made of electrical steel, with specific electromagnetic, thermal, and mechanical properties. The alloy contains silicon in order to obtain these qualities (Tong 2014). Electrical steel discs and laminations are stacked to form the cores. Laminations are preferably very thin and coated to keep electromagnetic and thermal losses low. Data was collected from Surahammars Bruk AB for non-oriented $300-\mu m$-thick laminations with $2 \%$ silicon and $0.4 \%$ aluminum and a coating of $3 \mu \mathrm{m}$ phenolic resin (Lindenmo 2015; Surahammars Bruk 2014a, b, 2015). For both reference machines, a conventional 48 slot stator design similar to that in the Toyota Prius 2004 (ANSYS 2011) was used. Likewise, based on observations of existing PMSM designs, the rotor core was designed as an interior permanent magnet machine,
Table 1 A summary of selected important geometric properties and other key parameters of the two reference machine datasets

\begin{tabular}{|c|c|c|c|c|c|c|}
\hline \multirow{2}{*}{$\begin{array}{l}\text { Reference machine } \\
\text { Scaled length }\end{array}$} & \multicolumn{3}{|l|}{ Small } & \multicolumn{3}{|l|}{ Large } \\
\hline & Shortest & Nominal & Longest & Shortest & Nominal & Longest \\
\hline \multicolumn{7}{|l|}{ General } \\
\hline Maximum torque & $48 \mathrm{Nm}$ & $96 \mathrm{Nm}$ & $191 \mathrm{Nm}$ & $119 \mathrm{Nm}$ & $239 \mathrm{Nm}$ & $477 \mathrm{Nm}$ \\
\hline Maximum power @ 4000 rpm & $20 \mathrm{~kW}$ & $40 \mathrm{~kW}$ & $80 \mathrm{~kW}$ & $50 \mathrm{~kW}$ & $100 \mathrm{~kW}$ & $200 \mathrm{~kW}$ \\
\hline Core stack lengths & $57 \mathrm{~mm}$ & $114 \mathrm{~mm}$ & $228 \mathrm{~mm}$ & $63 \mathrm{~mm}$ & $127 \mathrm{~mm}$ & $253 \mathrm{~mm}$ \\
\hline Maximum current density & $20 \mathrm{~A} / \mathrm{mm}^{2}$ & & & & & \\
\hline Maximum current @ 4000 rpm & $53 \mathrm{~A}$ & $105 \mathrm{~A}$ & $210 \mathrm{~A}$ & $166 \mathrm{~A}$ & $260 \mathrm{~A}$ & $607 \mathrm{~A}$ \\
\hline Number of poles & 8 & & & & & \\
\hline Air gap & $0.57 \mathrm{~mm}$ & & & $0.75 \mathrm{~mm}$ & & \\
\hline Parallel circuits per phase & 4 & & & & & \\
\hline \multicolumn{7}{|l|}{ Stator } \\
\hline Outer diameter & $152 \mathrm{~mm}$ & & & $200 \mathrm{~mm}$ & & \\
\hline Inner diameter & $103 \mathrm{~mm}$ & & & $135 \mathrm{~mm}$ & & \\
\hline Number of slots & 48 & & & & & \\
\hline Slot fill ratio & $45 \%$ & & & & & \\
\hline Turns per coil & 20 & 10 & 5 & 14 & 7 & 3 \\
\hline \multicolumn{7}{|l|}{ Rotor } \\
\hline Outer diameter & $101.5 \mathrm{~mm}$ & & & $133.5 \mathrm{~mm}$ & & \\
\hline Inner diameter, active core & $61 \mathrm{~mm}$ & & & $80 \mathrm{~mm}$ & & \\
\hline Magnet volume, per slot & $2.7 \mathrm{~cm}^{3}$ & $5.4 \mathrm{~cm}^{3}$ & $10.8 \mathrm{~cm}^{3}$ & $5.2 \mathrm{~cm}^{3}$ & $10.4 \mathrm{~cm}^{3}$ & $20.7 \mathrm{~cm}^{3}$ \\
\hline
\end{tabular}


with V-shape magnet slots for each of the eight poles (Ozpineci 2014).

Diameters and lengths were chosen with the aim to approximately reproduce how automotive electrical machine suppliers provide different motor series with different outer radiuses (Lenz 2011). The nominal lengths of the cores were determined through iterative calculations using ANSYS Maxwell (ANSYS 2015).

Next, a relationship between the torque and the core mass was established through calculations where each reference machine was scaled down to half, and up to double, in length. Magnetic and iron loss characteristics, and the mass density of $7600 \mathrm{~kg} / \mathrm{m}^{3}$, were collected from Surahammars Bruk (2015). The geometric dimensions of the machine core parts are presented in Table 1.

\subsection{Winding configuration and copper mass}

The reference machines have distributed windings with two layers of wire coils in each stator slot and eight poles (to match the rotor). Coils were grouped into four parallel branches, and the number of turns per coil was expected to vary with the stack length, in order to maintain the same maximum current density and base speed for all motors. Most important, the "fill factor," i.e., the part of the cross-section occupied by copper compared to the total area of each slot (also called "slot fill ratio"), was set to $45 \%$ in all machines, this being a typical value (Dutta et al. 2013).

However, windings do not only pass through the stator, actively contributing to the torque production. They also have passive sections, the end-windings, where the coils make turns from one slot to another to return back in a loop. A formula provided by Lindström (1999) was used to calculate the share of active versus passive conductor per turn, as well as the total weight of the different sections.

Furthermore, the copper used in phase conductors running from the terminal block to each branch has also been taken into account along with neutral interconnected return wires. The phase conductor mass was found to be small compared to that of the end-windings, and the passive amount of copper varies marginally compared to the variation of mass in the active sections when the reference machines are scaled in length.

\subsection{Stator insulation}

The current conducting wire placed in the stator slots is often referred to as "magnet wire," as its purpose is to form a magnetic field (Hitachi Metals 2015a), which will interact with the field created in the rotor by the magnets and rotor iron core. This typically consists of a copper base with one or multiple layers of insulation materials (Tong 2014). Enameled wire was selected for the motor design. This isolation consists of a hard glossy coating, made from polyester resins, polyamide resins, or alkyd resins (Hitachi Chemical 2015; Von Roll 2012; Hitachi Metals 2015a). As a simple approximation, based on observations of catalogued values (Von Roll 2012), it was assumed that the enamel coating layer increases the bare wire diameter by $10 \%$. Hence, a direct relation could be established between the copper and the enamel masses.

Furthermore, the coils must be firmly mounted, have good thermal conduction for heat dissipation, and isolated to be protected from short circuiting with each other and the stator core (Dorrell et al. 2011; Tong 2014). At the boundary to the core and between layers, foils are placed, called slot liners and separators. Also, the stator is impregnated to fill all remaining voids of the stator slots and within the bundles of the endwindings, for example with an epoxy compound or a silicone elastomer. Sometimes, the stator is fully encapsulated with impregnation to protect it from vibration, moist, and dirt. Additional insulation can be used in the end-turns between adjacent phases, in the form of glass cloth or plastic tapes or sheets, typically covered by mica, a type of silicate mineral (Von Roll 2007; Kauppinen 2014). The end-windings are often also laced with cords of nylon or cotton to further secure the installation (Essex Brownwell 1998). Finally, the phase conductors normally have some type of cover, additional to, or instead of, the enamel layer. Extruded cross-linked polymers are common insulation materials for such power cables (Hampton et al. 2007; Leoni 2014).

Data for all types of stator isolation and protection was gathered from various datasheets and combined with specialist consultations (Larrenduche 2015). For example, the slot liners and separators correspond to a type of rigid polyester foil called MYLAR (Dupont 2004; Carbex 2015), and the epoxy resin is suitable for several different processing methods and impregnation of stators for traction motors (Von Roll 2015).

\subsection{Permanent magnets}

Rare earth metals, such as neodymium, can be used to create very strong permanent magnets. Important properties of a magnet are remanence (magnetic strength), coercivity (resistance to demagnetization), and the energy product (the maximum magnetic energy density) (Lucas et al. 2015; Vaimann et al. 2013). Neodymium-iron-boron (NdFeB) magnets have a high-energy product and high remanence, as well as good mechanical properties for processing complex shapes (Lucas et al. 2015; Tong 2014). As a consequence, NdFeB magnets have become widely used for all types of magnet applications. However, magnet properties are temperature dependent, and ordinary $\mathrm{NdFeB}$ magnets are easily demagnetized at high temperature (Vaimann et al. 2013). Demagnetization occurs if the load on the magnet becomes too high, for example during faulty operation such as a short circuit. Moreover, occasional 
peak operating temperatures for magnets in traction motors can be above $150^{\circ} \mathrm{C}$, which is much higher than the typical maximum permitted working temperatures of an ordinary NdFeB magnet (Lucas et al. 2015).

Hence, in order to use $\mathrm{NdFeB}$ magnets for operation in vehicle traction motors, their thermal stability must be increased. This is ensured by adding specific heavy rare earth elements, e.g., dysprosium, to replace some of the neodymium (Brown et al. 2002; Yan et al. 2010; Vaimann et al. 2013). Common $\mathrm{Nd}(\mathrm{Dy}) \mathrm{FeB}$ magnet compositions consist of up to $10 \%$ dysprosium, $22-32 \%$ neodymium, $67-70 \%$ iron, and $1 \%$ boron (Yan et al. 2010; Gutfleisch et al. 2011; Fyhr et al. 2012). However, while increasing coercivity, dysprosium lowers the remanence (Brown et al. 2002; Vaimann et al. 2013). Also, it is expensive due to limited supply (Dorrell et al. 2011; Gutfleisch et al. 2011). Hence, dysprosium additions are preferably minimized but necessarily sufficient to accomplish most of the desired benefits. One solution to this balance problem is to add dysprosium at the boundaries between the grains of the magnet material (Yan et al. 2010; Vaimann et al. 2013; Hitachi 2014; Nakada et al. 2014). Data for such a low dysprosium grade $\mathrm{Nd}(\mathrm{Dy}) \mathrm{FeB}$ magnet was collected from Hitachi's NEOMAX-series (Hitachi 2014; Hitachi Metals, 2014a, b, 2015b) and used for the calculations. It contains about $4 \%$ dysprosium and has been rated to withstand operation at $140{ }^{\circ} \mathrm{C}$ (Hitachi Metals 2014a), which was judged as an acceptable trade-off between temperature stability and dysprosium content. The proportions of the $\mathrm{NdFeB}$ magnet base body were taken from Sprecher et al. (2014b) to become $26 \%$ neodymium, $4 \%$ dysprosium, $69 \%$ highly pure iron, and $1 \%$ boron in the final magnet before coating.

Another common way to reduce losses and avoid subsequent heat escalation in $\mathrm{NdFeB}$ magnets is to divide them into segments. This was assumed for the motor model (and important for the installation of the magnets), but without any specification for the exact arrangement, since losses inside the magnets have been shown to be very small for internal permanent magnet machines (Dutta et al. 2013).

Furthermore, $\mathrm{NdFeB}$ magnets corrode unless they are coated, and nickel is a commonly used coating material (Yan et al. 2010; Tong 2014; Lucas et al. 2015). A coating layer of 10 $15 \mu \mathrm{m}$ nickel, corresponding to $1 \%$ of the total magnet mass, was included in the model. Also, once placed in the rotor, there is typically a distance of $0.1 \mathrm{~mm}$ or more between the surface of the magnet and the core (Tremel et al. 2013). There are also cavities at the end of each magnet to provide magnetic flux barriers. Various casting resins can be used to fill these voids and to fixate the magnets, in order to improve heat dissipation and avoid mechanical friction. A methacrylate ester resin (Henkel 2010, 2015) was selected as the adhesive. Only a few grams are needed, i.e., significantly less than the amount of epoxy in the stator.

\subsection{Shaft and bearings}

The shaft transmits the torque produced by the motor to the external load and has to handle mechanical stress and strain during operation. It should be stiff and of low deflection. Carbon steel is the most common material used (Tong 2014). The geometrycan be solid or hollow, and varies largely with different designs, but generally, the diameter grows with increasing torque. Different machine shafts were compared, both for industrial machines (Baumüller 2014) and in automotive machines from Toyota, Nissan, and Volvo (Burress et al. 2011; Sato et al. 2011; Schwartz 2014), to establish a linear scaling from 20 to $50 \mathrm{~mm}$ of the average diameter with maximum torque, i.e., over $48-477 \mathrm{Nm}$. Next, the mechanical coupling to the mechanical drivetrain can have many different forms, e.g., flanges, splines, belts, or chains (Burress et al. 2011; Tong 2014). Splined teeth are robust and were found representative for the model, with the tooth depth and total number of teeth linked to the shaft diameter (Barsoum and Khan 2012; DIN 2006). Also, the shaft was scaled in length with the active core, plus a static section to connect with the bearings and the resolver, and for the splined coupling, in line with observations from literature (Miller 2013a). For simplicity, the mass of low-alloy medium carbon steel was then estimated from a uniform and solid shaft, including the average diameter over the splined section. The resulting shaft mass relates cubically to the torque input, since it is calculated from the shaft diameter and length, both in turn scaled with the torque.

Single-row all-steel ball bearings, matching the scaling of the shaft, were selected from a standard part catalogue (NSK 2013). Following the shaft dimensions, they were assumed to scale linearly with the torque, contributing with $80-280 \mathrm{~g}$ of low-alloyed bearing steel over the model span. The role of a bearing is to couple the housing and stator to the shaft and thereby carry the rotor package in its correct position inside the stator.

\subsection{Housing}

The housing contains the motor, acting as a frame holding it together. Two other main functions are protection and cooling. For automotive applications, cast aluminum is a typical material selection (Sato et al. 2011; Tong 2014; Johansson 2015). The housing consists of a casing encircling the stator as well as the end-windings and connection cables, referred to as the housing body, and two caps at the sides of the casing, referred to as endbells. Each endbell holds a bearing at the ends of the rotor core. The shape and mass of the housing may vary, largely depending on the stator form, the requirements for cooling and protection (e.g., the casting wall thickness), and the conditions for mounting the machine in the vehicle. 
Vehicle machines usually have liquid cooling (Sato et al. 2011; Nakada et al. 2014), and a coolant (water and glycol) is pumped through channels inside the housing body. Effective cooling, or the lack of it, has a direct influence on the capability, reliability, and lifetime of electrical machines. Especially, proper cooling is required to combine high performance with small size and low power consumption (Tong 2014). For this reason, unlike the other components in the LCI model, the housing parts were set to scale with the input maximum power value, without being recalculated to torque. Additionally, housings may sometimes be integrated with other powertrain parts, such as the gearbox. This has not been accounted for in the LCI model, but is a reason why the housing may be deselected by model users.

A rough, yet reasonable, estimation of the masses of the housing parts was made by comparing detailed and measured machine housing data for the 2007 Toyota Camry, 2008 Lexus LS 600h, 2010 Toyota Prius, and the 2011 Nissan Leaf (Burress et al. 2011; Sato et al. 2011; Burress and Campbell 2013; Burress 2013; Miller 2013a; Shimizu et al. 2013). The resulting power-to-mass relationships are shown in Fig. 5. A similar relationship based on the same assumed geometry was also established for a coating of the aluminum housing. Coatings are sometimes used, despite the inherent corrosion resistance of aluminum, to add protection. Data was gathered for a clear alkyd resin varnish intended for electrical machine housings, resulting in a small mass contribution ranging from about 90 to $300 \mathrm{~g}$.

\subsection{Other subparts}

In order to build a fully functioning electrical traction machine, some additional subcomponents are required. A position resolver

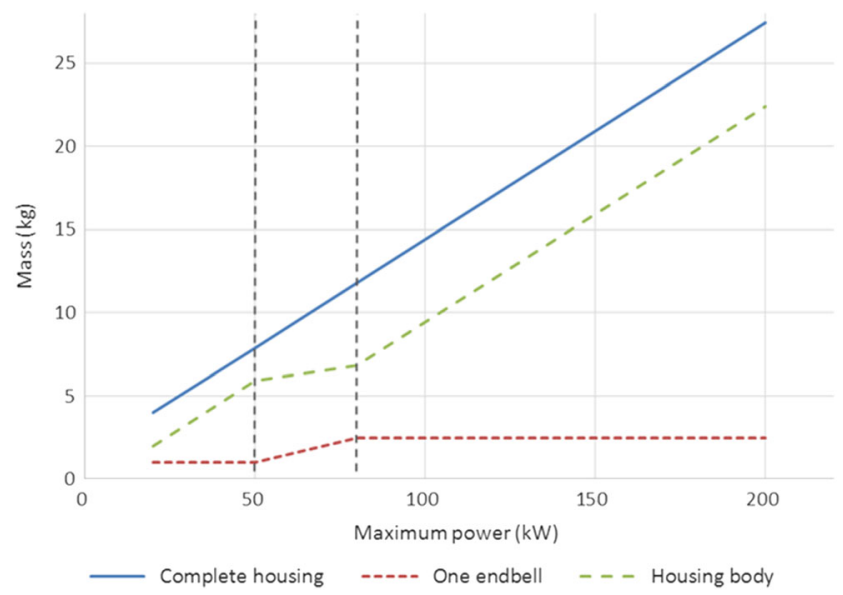

Fig. 5 The estimation of the housing parts' masses (and total mass) as a function of the input maximum motor power. The section between the dotted lines represents the overlap span of the two reference machines, i.e., where the housing shifts in diameter size. For additional details on constants and how the dataset was established, please read the model report (Nordelöf et al. 2016) is used to decide the angular position of the rotor so that the motor can be properly controlled for electric vehicle propulsion (Kisner et al. 2012). A variable reluctance resolver of only $76 \mathrm{~g}$ was included in the design based on data from Tamagawa (2014). It generates an analog signal, which is converted to a digital signal by the motor control unit, referred to as the inverter. The resolver is constructed as a small electrical machine with steel laminations, copper coils, and a plastic frame.

Additionally, the motor is equipped with a terminal block to fasten cables or bus bars coming from the inverter. The structure and size of this plastic block with galvanized steel connection plates was estimated based on observations made in Shimizu et al. (2013). In order to be connected to the same part from the other side, the phase conductors are pinned with tin plated copper lugs. The complete motor also includes an estimate for galvanized steel bolts, nuts, and washers, which secure the endbells to the housing body.

\section{Results from and evaluation of the model}

Three different types of electric motor design results were generated in the LCI model work. They are presented in the following chapter. First, the design tool calculations provided performance results for the reference machines. Second, the model itself generates mass and material configuration results. Finally, the model's mass predictions were compared with real-world motors to validate the model.

\subsection{Machine performance}

The design tool calculations were conducted iteratively in several simulations to determine the maximum torque and power of the small and large reference machines. The number of winding turns was then adjusted so that a maximum DC voltage level of $430 \mathrm{~V}$ can be maintained, irrespective of core stack length. The maximum current ${ }^{3}$ for the reference machines at nominal length was calculated to be 105 and 260 A respectively, and a relationship for torque and power with speed and electromagnetic losses was established for different working points of the machines. Resulting maximum efficiencies were found to be 96-97\%, which is in line with what is found in existing automotive applications (Burress et al. 2011). As an example, the combined efficiency map and torque-speed diagram for the large reference machine at the nominal length is shown in Fig. 6.

\subsection{Model results}

The complete mass curve generated by the LCI model over the complete torque span of $48-477 \mathrm{Nm}$ with the default base

\footnotetext{
${ }^{3}$ RMS phase current
} 


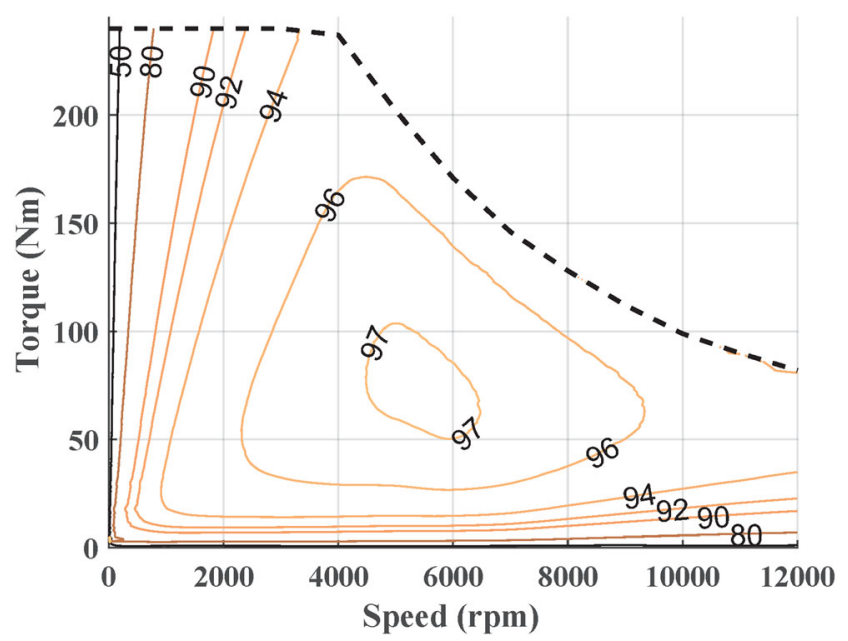

Fig. 6 The combined diagram for the electromagnetic efficiency and the torque-speed relationship of the machine design for $100 \mathrm{~kW}$ at $4000 \mathrm{rpm}$ (the default setting of the model, matching the large reference machine at nominal length)

speed (4000 rpm) is shown in Fig. 7, including how the two underlying reference machine datasets were combined into one. Evidently, the relationship between the user input of maximum torque (entered as torque directly or recalculated from power) and the predicted mass is predominantly linear over the modelled operating range. This is in accordance with fundamental electric motor theory and expected since the model was based on lengthwise scaling of the active components, when all other parameters were held fix to match a typical automotive design. The simplified housing scaling model further reinforces the linear properties of the results, while other scaling features, such as the shaft diameter growth, only have a minor effect on the overall mass prediction.

However, more detailed effects of scaling are revealed in the material configuration results for the different subparts of the motor. Figure 8 shows such results generated by the model for 20,80 , and $200 \mathrm{~kW}$ of maximum power at $4000 \mathrm{rpm}$. For comparison, it also presents measured values for the real $80 \mathrm{~kW} 2012$ Nissan Leaf motor (Miller 2013a). As shown, the share of electrical steel grows with increasing motor size, while the share of copper decreases. It can also be noted that the mass fraction of low-alloyed steel, i.e., the shaft, varies irregularly. The full result list in the LCI model file contains 20 different materials. The mass configuration generated by the model and 2012 Nissan Leaf motor at $80 \mathrm{~kW}$ shows relatively good correlation, with the biggest relative differences found in the amount of insulation and carbon steel, i.e., passive parts where design variability is large.

\subsection{Comparison with recent real-world electrical machine data}

Figure 9 shows a section of the total torque span, where the LCI model results have been compared with real-world data in order to validate the quality of its estimations. Seven electric motors are included in the comparison, whereof three are presented with different ratings for power at the same torque (i.e., differently rated voltages and related base speeds), in total providing ten examples of tabulated data for electric motors. These motors are marked with $\mathrm{a}$ and $\mathrm{b}$ for the different power ratings. The details of the data presented in Fig. 9 are given in Table 2.

Table 2 and Fig. 9 show that the real-world data deviates $1-$ $21 \%$ from the estimates of total mass made by the LCI model. As expected, there is noticeable variability in electric motor design for vehicles, also for similar power and torque requirements. This presents a challenge for any type of generic electrical machine model, which aims to combine easily accessed input data with a readily used calculation procedure. However, as also seen in Fig. 9, results indicate that the LCI model provides motor mass estimations that form a rough but
Fig. 7 The LCI model results with the default setting for base speed (4000 rpm), including the stepwise interpolation between the small to the large reference machine into one seamless model

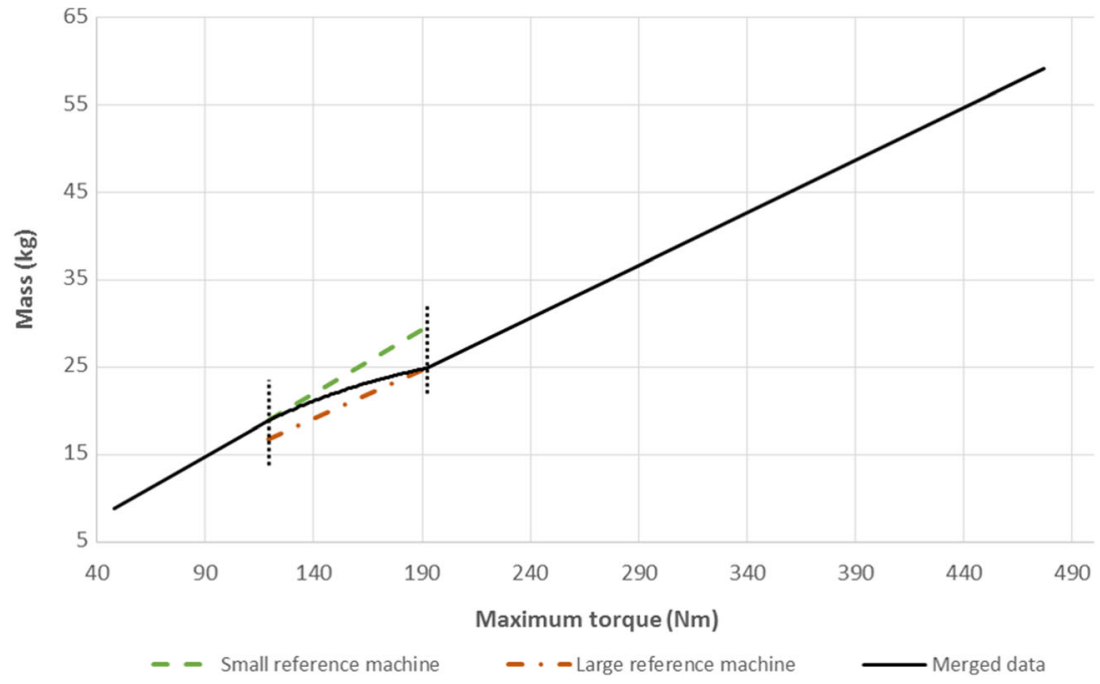


LCl model, $20 \mathrm{~kW}$ :

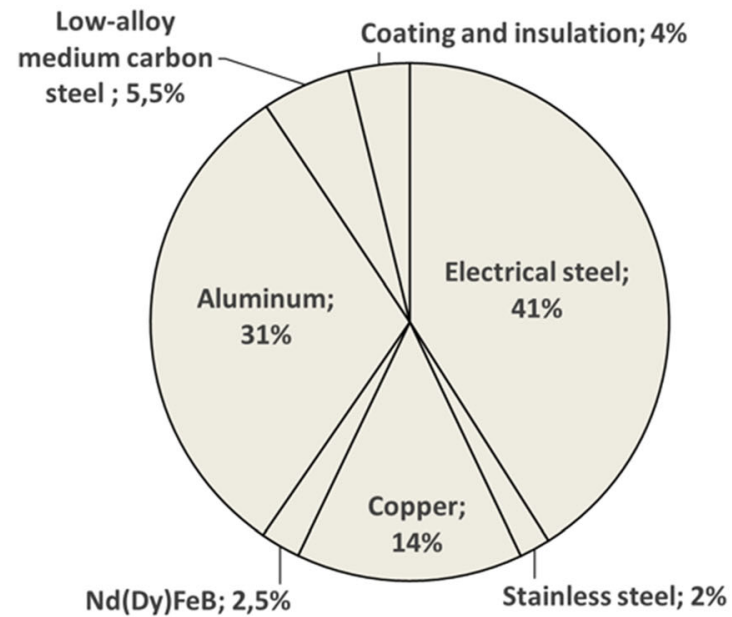

$\mathrm{LCl}$ model, $80 \mathrm{~kW}$ :

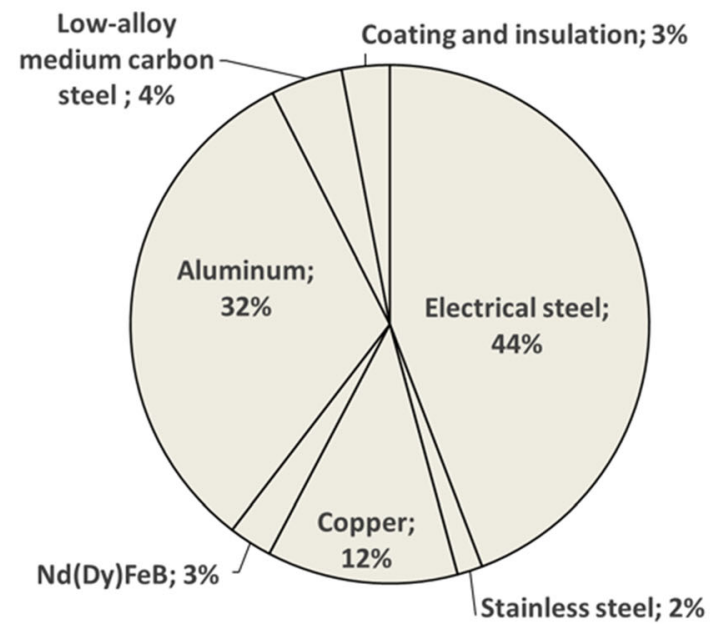

$\mathrm{LCl}$ model, $200 \mathrm{~kW}$ :

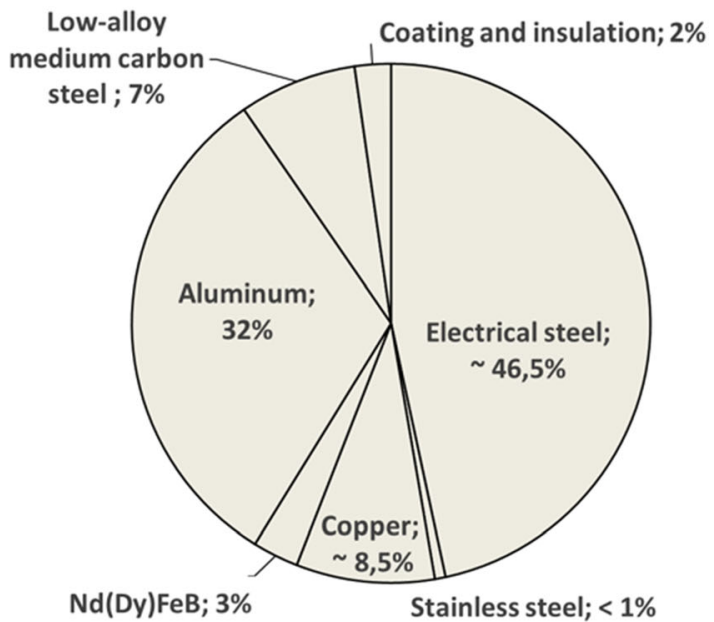

Nissan Leaf $2012(80 \mathrm{~kW})$

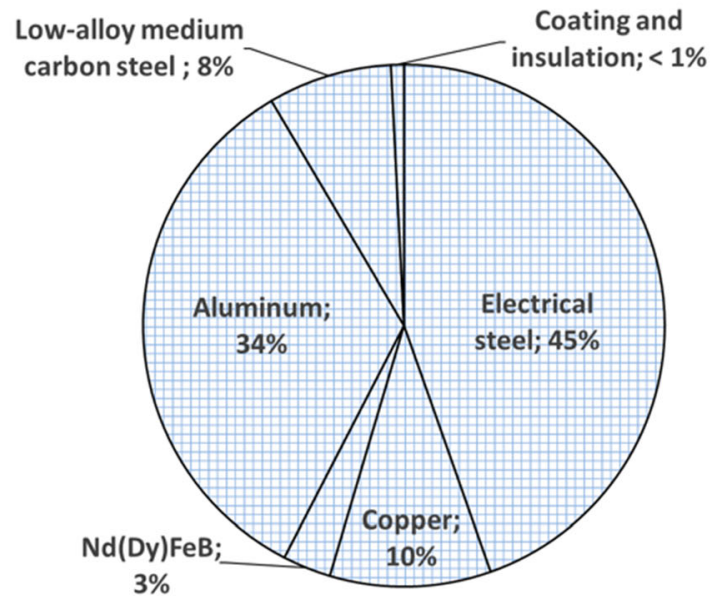

Fig. 8 The LCI model results for the material configuration at three different maximum power values with the default setting for base speed (4000 rpm), and a comparison with the material configuration of the 2012 Nissan Leaf (the pie chart in the lower right corner) as reported by Miller (2013a)

reasonable median in comparison to the pattern created by all data points.

The 2013 Nissan Leaf motor (number 1 in Table 2 and Fig. 9) is among those that deviate most, by $19 \%$. An important part of the explanation is that Nissan provides the maximum power rating on a powertrain level, where the inverter and battery limit the power performance, rather than the electrical machine itself. Hence, our model underestimates the housing mass. In fact, an earlier model (2011) of the Nissan Leaf electrical machine (identical to the mass composition reference shown in Fig. 8) was shown capable of operating continuously at its rated peak value $(80 \mathrm{~kW})$, and tests indicate that much higher power levels are possible (Burress and Campbell 2013; Miller 2013b). (For further discussion, see the model report section 4.3.1 (Nordelöf et al. 2016).)
Similarly, in order not to promise too much, a vehicle manufacturer may choose to specify the peak power for the worst case battery voltage, instead of the rated voltage. These types of peak power definition mismatches are important to take into consideration when using the LCI model for mass predictions, and in any situation when relating the motor mass to the specified value for maximum power. For the 2013 Nissan Leaf, the motor was downsized in weight, but from observations, it can be concluded that the housing is relatively even larger, due to other structural design considerations and not only heat dissipation (Miller 2013a; Shimizu et al. 2013).

Oppositely, one of the electrical machines from Brusa (5.ab) and the Fiat 500e motor (6) weigh $13-18 \%$ less than the results of the model calculations. Observations of these motor designs show they all have relatively slender housings (Bosch 
Fig. 9 The LCI model results for total electric motor mass compared with real-world electric vehicle traction machine data (with the same numbering as in Table 2). The estimated base speed for each plotted machine is stated in Table 2

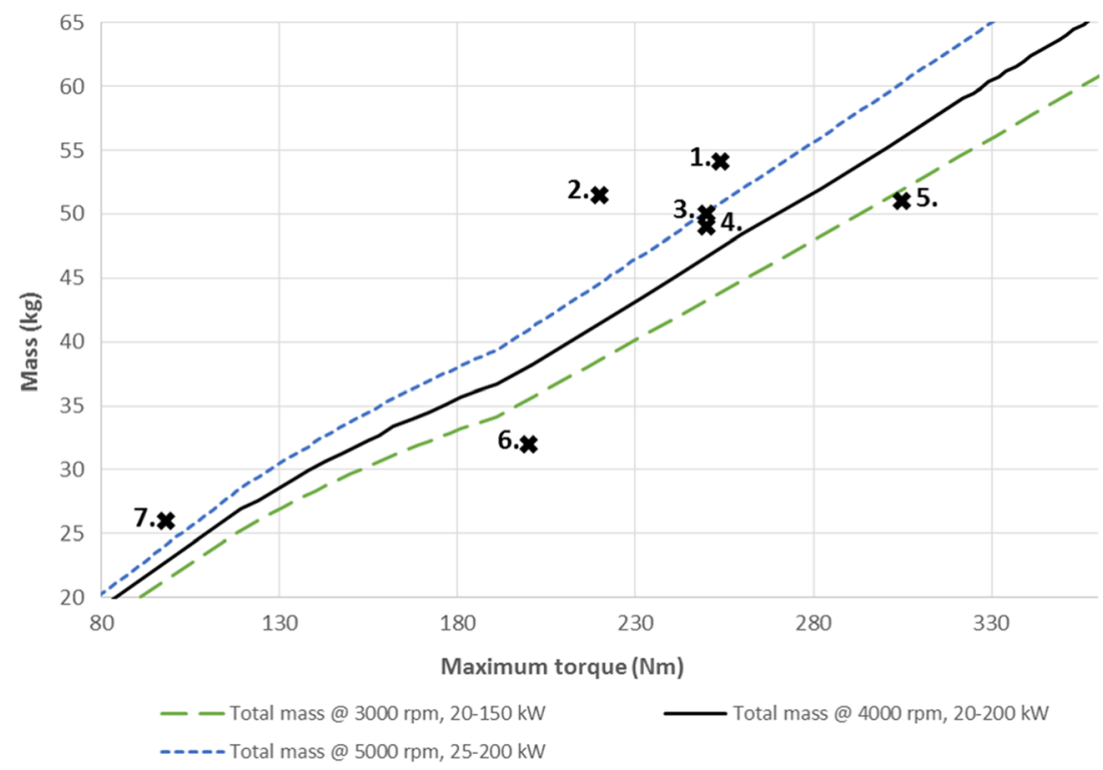

2013; Brusa 2013), indicating again that the housing size and design are an important source of variability. Hence, if high precision is sought when estimating the mass and composition of a specific PMSM design, the model uncertainty can be reduced by making case-specific estimations of the housing weights, and using the option to exclude the housing from the model calculation.

The heaviest Brusa motor (2.a-b) deviates most from the model results by $21 \%$ and $18 \%$. Similar to the Volvo C30E motor (3) and the lightest Brusa motor (7.a-b), it is heavier than the model prediction. Typical design features that can explain such a divergence is the combination of high performance with high efficiency. Generally, increased current density and stronger magnets lead to better performance in a smaller and lighter design, but at the cost of a lower efficiency. However, if the motor is allowed to be larger and heavier, high efficiency is more easily accomplished in combination with performance. Still, it is notable that all comparisons with realworld motors are within the target of $25 \%$ prediction accuracy.

Furthermore, designing electrical machines for vehicle traction applications involves balancing several different types of requirements, e.g., electromagnetic, mechanical (including vibrations and acoustics), and thermal, (Tong 2014). If the engineering process is iterative and system oriented, design trade-offs may be well balanced, both within the electric motor and with other powertrain parts. For example, an increased current demand will impact the selection of inverter, which generally must be larger in order to supply a higher current. Oppositely, when striving for short design time, the subparts of a motor are sometimes designed more or less independently, and then assembled into one unit in a bottom-up component approach (Tong 2014). The motor as a whole might then

Table 2 The LCI model results for total electric motor mass compared with real-world electric vehicle traction machine data (with the same numbering depicted in Fig. 9)

\begin{tabular}{|c|c|c|c|c|c|c|c|c|c|}
\hline No. & Model (year) & $\begin{array}{l}\text { Max. power } \\
(\mathrm{kW})\end{array}$ & $\begin{array}{l}\text { Max. torque } \\
(\mathrm{Nm})\end{array}$ & $\begin{array}{l}\text { Voltage } \\
\text { (V) }\end{array}$ & $\begin{array}{l}\text { Est. base speed } \\
\text { (rpm) }\end{array}$ & $\begin{array}{l}\text { Real mass } \\
(\mathrm{kg})\end{array}$ & $\begin{array}{l}\text { Pred. mass } \\
(\mathrm{kg})\end{array}$ & $\begin{array}{l}\text { Diff. } \\
(\%)\end{array}$ & Source \\
\hline 1. & Nissan Leaf (2013) & 80 & 254 & 400 & 3000 & 54 & 43.9 & 19 & Shimizu et al. (2013) \\
\hline 2.a & Brusa HSM1 (6.17.12) & 87 & 220 & 360 & 3800 & 51.5 & 40.9 & 21 & Brusa (2013) \\
\hline 2.b & & 96 & 220 & 400 & 4200 & 51.5 & 42.1 & 18 & Brusa (2013) \\
\hline 3. & Volvo C30 E (2013) & 89 & 250 & 400 & 3300 & 50 & 44.6 & 11 & Siemens $(2013,2015)$ \\
\hline 4. & BMW i3 (2014) & 125 & 250 & 400 & 4800 & 49 & 49.4 & 1 & BMW (2014) \\
\hline 5.a & Brusa HSM1 (10.18.13) & 140 & 305 & 360 & 4400 & 51 & 57.7 & 13 & Brusa (2013) \\
\hline 5.b & & 156 & 305 & 400 & 4900 & 51 & 59.8 & 17 & Brusa (2013) \\
\hline 6. & Fiat 500e (2013) & 80 & 200 & 430 & 3800 & 32 & 37.7 & 18 & Bosch (2013) \\
\hline 7.a & Brusa HSM1 (10.18.04) & 45 & 98 & 360 & 4400 & 26 & 23.2 & 11 & Brusa (2016) \\
\hline $7 . b$ & & 51 & 98 & 400 & 5000 & 26 & 24.0 & 8 & Brusa (2016) \\
\hline
\end{tabular}


perform less well, or otherwise be oversized in one or several aspects. Geometric constraints are also common, e.g., the available packaging space for the machine. It is often not possible for a vehicle manufacturer to obtain an ideal motor at a low price. Typically, a good price can be obtained by using a design that the machine supplier has sold to some other customer, possibly with moderate modifications, for example by adjusting the length.

\section{Conclusions}

A new scalable LCI model which estimates the mass and material configuration of a typical PMSM design for automotive electric driving applications has been presented. This article, part one of two, has shown how the model relies on thorough design data collection and on fundamental electromagnetic principles for estimating and scaling masses from easily accessible input data, i.e., power and torque. The structure and technical scope of the model has been explained. Calculations show that the selected motor designs have good efficiency, suitable for electric propulsion of vehicles.

It has also been presented and exemplified how some user options, such as the possibility of deselecting major passive subparts, most notably the housing, can increase model precision if the aim is to estimate the mass of a PMSM where that passive part has a specific design for which data can be collected separately.

Lastly, the comparison with recently published data for real electrical traction machines has shown that the LCI model generates reasonable and representative mass data, despite a deviation of around $20 \%$ from some example motors. This difference is concluded to fall within the expectations for a good result, since there is noticeable variability in the design, even for the same machine type and similar requirements. Hence, for LCA of electrical machines in automotive traction applications, the LCI model may be used as a generic estimation of a PMSM, when specific data is lacking.

\section{Accessing the LCI model file and model report}

The life cycle inventory model file (Nordelöf 2016) and the model report (Nordelöf et al. 2016) can be downloaded from the SPINE database provided by Swedish Life Cycle Center: http://cpmdatabase.cpm.chalmers.se/Scripts/sheet.asp? ActId=JT-2016-06-21-39

Acknowledgements The authors would like to express their gratitude to the Swedish Electromobility Centre and to the Area of Advance Energy at Chalmers University of Technology for financing the project, thus stimulating the cross-disciplinary research cooperation.
Open Access This article is distributed under the terms of the Creative Commons Attribution 4.0 International License (http:// creativecommons.org/licenses/by/4.0/), which permits unrestricted use, distribution, and reproduction in any medium, provided you give appropriate credit to the original author(s) and the source, provide a link to the Creative Commons license, and indicate if changes were made.

\section{References}

ANSYS (2011) Study of a Permanent Magnet Motor with MAXWELL 3D: example of the 2004 Prius IPM Motor. Ansoft Maxwell Field Simulator: Topic - Motor Application Note 1.1, Maxwell 3D, version 11. ANSYS, Inc. (Tutorial example from Ansoft Maxwell)

ANSYS (2015) ANSYS® Electromagnetic Suite, Maxwell 2015.1.0. 16.1.0 edn. ANSYS, Inc. (Electrical machine design and evaluation software)

Barré O, Napame B (2016) Concentrated windings in compact permanent magnet synchronous generators: managing efficiency. Mach Des 4(1):2

Barsoum I, Khan F (2012) Strength optimization of induction hardened splined shaft - material and geometric aspects. Int J Mech Aerosp Ind Mechatron Manuf Eng 6(3):676-679

Baumüller (2014) Three-phase synchronous motors DSP1-045-100. Baumüller Nürnberg GmbH, Germany (Product catalogue)

BMW (2014) Technical training. Product information. 01 high-voltage components. BMW Service / BWM Group University, BMW AG, Munich (Documentation for technical training. BV-72/Technical Training. ST1403a for US Market)

Bosch (2013) Bosch SMG 180/120 electric motor: compact powerhouse. Flaig F. Bosch media service, The Bosch Group. (Pressrelease PI8106 for Bosch motor in Fiat 500E and Peugeot 3008)

Brown D, Ma B-M, Chen Z (2002) Developments in the processing and properties of NdFeb-type permanent magnets. J Magn Magn Mater 248(3):432-440

Brusa (2013) HSM1 - hybrid synchronous motor-optimum performance from zero speed. BRUSA Elektronik AG, Switzerland (Electrical traction machine specifications for HSM1-6.7.12 and 10.18.13)

Brusa (2016) HSM1 - hybrid synchronous motor $50 \mathrm{~kW}$-powerful Drive for small vehicles. BRUSA Elektronik AG, Switzerland (Electrical traction machine specifications for HSM1-10.18.04)

Burress T (2013) Benchmarking state-of-the-art technologies project ID: APE006. Paper presented at the 2013 U.S. DOE Hydrogen and Fuel Cells Program and Vehicle Technologies Program Annual Merit Review and Peer Evaluation Meeting, May 14

Burress T, Campbell S (2013) Benchmarking EV and HEV power electronics and electric machines. Paper presented at the Transportation Electrification Conference and Expo (ITEC), 2013 I.E. Detroit, MI, USA, 16-19 June

Burress TA, Campbell SL, Coomer CL, Ayers CW, Wereszczak AA, Cunningham JP, Marlino LD, Seiber LE, Lin HT (2011) Evaluation of the 2010 Toyota Prius Hybrid Synergy Drive System. Olszewski M. Electrical and Electronics Systems Research Division, Oak Ridge National Laboratory, US Department of Energy, USA

Carbex (2015) Carbex inside-Produktinformation: Polyesterfilm MYLAR a. Carbex AB, Sweden (Product datasheet from local supplier)

Chan CC (2007) The state of the art of electric, hybrid, and fuel cell vehicles. Proc IEEE 95(4):704-718

Choe Y-Y, Oh S-Y, Ham S-H, Jang I-S, Cho S-Y, Lee J, Ko K-C (2012) Comparison of concentrated and distributed winding in an IPMSM for vehicle traction. Energy Procedia 14:1368-1373 
Del Duce A, Gauch M, Althaus H-J (2016) Electric passenger car transport and passenger car life cycle inventories in ecoinvent version 3. Int J Life Cycle Assess 21:1314-1326

DIN (2006) Splined connections with involute splines based on reference diameters - part 1: principles. DIN Deutsches Institut für Normung e. V, Germany (German splining standard DIN 5480-1)

Dorrell DG, Hsieh M, Popescu M, Evans L, Staton DA, Grout V (2011) A review of the design issues and techniques for radial-flux brushless surface and internal rare-earth permanent-magnet motors. IEEE Trans Ind Electron 58(9):3741-3757

Dupont (2004) Material data safety sheet-MYLAR polyester film. DuPont Teijin Films, U.S. Limited Partnership, USA (OEM MSDS for insulation foil)

Dutta R, Chong L, Rahman FM (2013) Analysis and experimental verification of losses in a concentrated wound interior permanent magnet machine. Prog Electromagn Res B Pier B 48:221-248

Essex Brownwell (1998) Motor repair supplies. Essex Group, Inc., USA (Product catalogue for electric motor parts and accessories)

Fyhr P, Stahl J, Andersson M (2012) The scale of permanent magnet materials for automotive traction motors. Paper presented at the Electric Drives Production Conference (EDPC), 2012 2nd International, Nuremberg, Germany, 15-18 Oct. 2012

Gutfleisch O, Willard MA, Brück E, Chen CH, Sankar SG, Liu JP (2011) Magnetic materials and devices for the 21st century: stronger, lighter, and more energy efficient. Adv Mater 23(7):821-842. doi:10. 1002/adma.201002180

Hampton N, Hartlein R, Lennartsson H, Orton H, Ramachandran R (2007) Long-life XLPE Insulated Power Cable. Paper presented at the JICABLE'07-7th International Conference on Power Insulated Cables, Versailles, June 24th-28th

Hawkins T, Gausen O, Strømman A (2012) Environmental impacts of hybrid and electric vehicles - a review. Int J Life Cycle Assess 17(8):997-1014

Hendershot JR, Miller TJE (2010) Design of brushless permanentmagnet machines, 2nd edn. Motor Design Books LLC, USA

Henkel (2010) Loctite ${ }^{\circledR}$ Threadlocker, Red $271^{\mathrm{TM}}$. Henkel Corporation, USA (Product datasheet, ref. no. 120271)

Henkel (2015) Safety data sheet—Loctite ${ }^{\circledR}$ Threadlocker, red $271^{\mathrm{TM}}$. Henkel Corporation, USA (MSDS for anaerobic sealant)

Hitachi (2014) Special issue "Hitachi Technology 2014". 63(3)

Hitachi Chemical (2015) Insulating Varnishes. Hitachi Chemical Co., Ltd. http://www.hitachi-chem.co.jp/english/products/eim/001.html. Accessed 23 June 2015

Hitachi Metals (2014a) NEOMAX® series-demagnitization curve. Hitachi Metals, Ltd., Japan (Demagnitization datasheet for Neomax series)

Hitachi Metals (2014b) Permanent magnets. Hitachi Metals, Ltd., Japan (Product catalogue for Neomax series)

Hitachi Metals (2015a) Magnet wire - selection and use directions for magnet wire. Hitachi Metals, Ltd., Japan (Product catalogue)

Hitachi Metals (2015b) Neodymium-iron-boron magnets NEOMAX®_properties. Hitachi Metals, Ltd, Japan http://www.hitachi-metals.co. jp/e/products/auto/el/p03 21.html. Accessed September 242015

Johansson J (2015) Technical specialist of electrical machine mechnical design, Aros Electronics AB and IRO AB. Van de Wiele Group, Ulricehamn Personal communication with Nordelöf A. June 10:th, 11 :th and 12:th, 2015

Kauppinen J (2014) Redesigning the coil end insulation of electrical motor. Vasa University of Applied Sciences, Finland

Kisner R, Melin A, Burress T, Fugate D, Holcomb D, Wilgen J, Miller J, Wilson D, Silva, Whitlow L, Peretz F (2012) Embedded sensors and controls to improve component performance and reliability conceptual design report. Measurement Science and Systems Engineering Division, Oak Ridge National Laboratory, US Department of Energy, USA
Larrenduche D (2015) Global Product Line Manager, Vice President Product Line Management, Von Roll Isola France SA. Personal Communication with Nordelöf A. September 5:th and 7:th, and October 28:th, 2015

Lenz M (2011) Individual E-mobility system solutions for automotive and off-highway applications. Paper presented at the Eco-mobility 2011, Austrian Association for Advanced Propulsion Systems 6:th International Conference, Vienna, November 15

Leoni (2014) LEONI Automotive Cables. Leoni Kabel GmbH, Germany (Product catalogue for automotive cables)

Lindenmo M (2015) Manager development and technical customer support, Cogent Power / Surahammars Bruk AB. Personal communication with Nordelöf A. June 21:st and 25:th, and August 21:st, 2015

Lindström J (1999) Development of an experimental permanent-magnet motor drive. Licentiante Thesis at the School of Electrical and Computer Engineering, Chalmers University of Technology, Göteborg

Lucas J, Lucas P, Le Mercier T, Rollat A, Davenport WGI (2015) Rare earths - science, technology. Production and Use Elsevier B.V, Amsterdam

Miller JM (2013a) Electric Motor R\&D Project ID: APE051. Paper presented at the 2013 U.S. DOE Hydrogen and Fuel Cells Program and Vehicle Technologies Program Annual Merit Review and Peer Evaluation Meeting, May 15

Miller JM (2013b) Oak Ridge National Laboratory Annual Progress Report for the Power Electronics and Electric Motors Program. Annual Progress Report-Advanced Power Electronics and Electric Motors. November, 2013b: ORNL/TM-2013/498. Electrical and Electronics Systems Research Division, Oak Ridge National Laboratory, US Department of Energy, USA

Nakada T, Ishikawa S, Oki S (2014) Development of an electric motor for a newly developed electric vehicle. SAE Technical Paper 2014-011879. SAE International. doi:10.4271/2014-01-1879

NETL (2015) NETL Unit Process Library. U.S. Department of Energy, National Energy Technology Laboratory. http://www.netl.doe.gov/ research/energy-analysis/life-cycle-analysis/unit-process-library. Accessed 29 Oct 2015

Nordelöf A (2016) Scalable IPMSM LCI Model.xlsm [Online]. Version 1.0. Gothenburg: Environmental Systems Analysis; Chalmers University of Technology. Distributed by The Swedish Life Cycle Center. Available: http://cpmdatabase.cpm.chalmers.se/Scripts/ sheet.asp?ActId=JT-2016-06-21-39. (Gate to gate life cycle inventory in Microsoft Excel Macro-Enabled Worksheet)

Nordelöf A, Messagie M, Tillman A-M, Ljunggren Söderman M, Van Mierlo J (2014) Environmental impacts of hybrid, plug-in hybrid, and battery electric vehicles - what can we learn from life cycle assessment? Int J Life Cycle Assess 19(11):1866-1890

Nordelöf A, Grunditz E, Tillman A-M, Thiringer T, Alatalo M (2016) A Scalable life cycle inventory of an electrical automotive traction machine - technical and methodological description, version 1.0. 2016: Report No. 2016:4. Department of Energy and Environment, Divisions of Environmental Systems Analysis \& Electric Power Engineering, Chalmers University of Technology, Gothenburg

NSK (2013) Roller Bearings. NSK Ltd., Tokyo (Product catalogue)

Ozpineci B (2011) Oak Ridge National Laboratory Annual Progress Report for the Power Electronics and Electric Machinery Program. Annual Progress Report-Power Electronics and Electric Machines. October, 2011: ORNL/TM-2011/263. Energy and Transportation Science Division, Oak Ridge National Laboratory, US Department of Energy, USA

Ozpineci B (2014) Oak Ridge National Laboratory Annual Progress Report for the Power Electronics and Electric Motors Program. Annual Progress Report-Advanced Power Electronics and Electric Motors. November, 2014: ORNL/SPR-2014/532. 
Electrical and Electronics Systems Research Division, Oak Ridge National Laboratory, US Department of Energy, USA

Ramakrishnan K, Stipetic S, Gobbi M, Mastinu G Multi-objective optimization of electric vehicle powertrain using scalable saturated motor model. In: 2016 Eleventh International Conference on Ecological Vehicles and Renewable Energies (EVER), 6-8 April 2016 2016. pp 1-6. doi:10.1109/EVER.2016.7476430

Sato Y, Ishikawa S, Okubo T, Abe M, Tamai K (2011) Development of high response motor and inverter system for the Nissan LEAF Electric Vehicle. SAE Technical Paper 2011-01-0350. SAE International. doi:10.4271/2011-01-0350

Schwartz J (2014) Electric motor installation for improved vehicle noise characteristics. Thesis for the degree of Master of Science, Lund University, Lund

Shimizu H, Okubo T, Hirano I, Ishikawa S, Abe M (2013) Development of an integrated electrified powertrain for a newly developed electric vehicle. SAE Technical Paper 2013-01-1759. SAE International. doi:10.4271/2013-01-1759

Siemens (2013) Inside e-Car. Siemens AG, Germany (Powerpoint presentation from Siemens AG)

Siemens (2015) Volvo C30 electric-Siemens fleet in cooperation with Volvo car Corporation. eCar Powertrain Systems, Siemens AG, Nuremberg (Technical datasheet from Siemens AG, E80001-A80P700-X-7600)

Sizov GY, Ionel DM, Demerdash NAO Multi-objective optimization of PM AC machines using computationally efficient-FEA and differential evolution. In: 2011 I.E. International Electric Machines \& Drives Conference (IEMDC), 15-18 May 2011 2011. pp 15281533. doi:10.1109/IEMDC.2011.5994836

Sprecher B, Xiao Y, Walton A, Speight J, Harris R, Kleijn R, Visser G, Kramer GJ (2014a) Life cycle inventory of the production of rare earths and the subsequent production of $\mathrm{NdFeB}$ rare earth permanent magnets. Environ Sci Technol 48(7):3951-3958

Sprecher B, Xiao Y, Walton A, Speight J, Harris R, Kleijn R, Visser G, Kramer GJ (2014b) Life cycle inventory of the production of rare earths and the subsequent production of $\mathrm{NdFeB}$ rare earth permanent magnets - supporting information. Institute of Environmental
Sciences (CML), Leiden University, The Netherlands. (Supporting Information for Environmental Science \& Technology

Surahammars Bruk (2014a) Hi-Lite - electrical steel for next generation designs. Cogent Power Inc. Tata Steel Europe, Tata Group (Product catalogue)

Surahammars Bruk (2014b) Non oriented electrical steel. Cogent Power Inc. Tata Steel Europe, Tata Group (Product catalogue)

Surahammars Bruk (2015) Hi-Lite-NO30. Cogent Power Inc. Tata Steel Europe, Tata Group. (Datasheet)

Tamagawa (2014) VR type resolver Singlsyn — super-thin angle sensor (absolute type). Tamagawa Seiki CO., Ltd., Japan (Product catalogue T12-1570N13)

Tong W (2014) Mechanical design of electric motors. CRC Press, Taylor \& Francis Group, Boca Raton

Tremel J, Hofmann B, Risch F (2013) Handling and fixation of permanent magnets. Adv Mater Res 769:3-10

Vaimann T, Kallaste A, Kilk A, Belahcen A Magnetic properties of reduced Dy NdFeB permanent magnets and their usage in electrical machines. In: AFRICON, 2013, 9-12 2013. pp 1-5. doi:10.1109/ AFRCON.2013.6757787

Volvo (2015) Volvo Electric Concept Bus. Volvo Bus Corporation, Sweden (Product datasheet for Volvo's all electric concept bus, BED 00685.15.05 SE)

Von Roll (2007) Low voltage materials and systems. Von Roll USA, Inc., USA (Product catalogue)

Von Roll (2012) Winding Wires and Litz Wires. Von Roll Holding AG, Switzerland (Product catalogue)

Von Roll (2015) Resin—Damisol® 3500 HTC. Von Roll France SA, France (Product datasheet)

Weidema BP, Bauer C, Hischier R, Mutel C, Nemecek T, Reinhard J, Vadenbo CO, Wernet G (2013) The ecoinvent database: overview and methodology. Data quality guideline for the Ecoinvent database version 3. The Centre for Life Cycle Inventories. www.ecoinvent. org. 2014-2016

Yan G, McGuiness PJ, Farr JPG, Harris IR (2010) Optimisation of the processing of $\mathrm{Nd}-\mathrm{Fe}-\mathrm{B}$ with dysprosium addition. J Alloy Compd 491(1-2):L20-L24 